\title{
Obstructive jaundice with a biliary clot post-endoscopic sphincterotomy treated with clipping and endoscopic biliary stenting
}

A 62-year-old man was admitted with epigastralgia. He had a history of laparoscopic cholecystectomy for cholecystolithiasis. He had no coagulopathy and was not taking anticoagulants. Abdominal computed tomography (CT) showed a common bile duct (CBD) stone ( $\triangleright$ Fig. $1 \mathrm{a})$. Endoscopic retrograde cholangiography (ERC) and intraductal ultrasonography (IDUS) also showed a $2.8-\mathrm{mm}$ CBD stone ( $\mathbf{F i g} \mathbf{1} \mathbf{b}$, $>$ Fig. $\mathbf{2} \mathbf{a}, \mathbf{b}$ ). Endoscopic sphincterotomy (EST) was performed ( Fig. 2c) and the CBD stone was removed using a wire basket ( $\triangleright$ Fig. 2d).

The patient complained of epigastralgia again after 4 days. Laboratory investigations demonstrated elevated cholestatic parameters: total bilirubin $2.8 \mathrm{mg} / \mathrm{dL}$ (normal range $0.4-1.5 \mathrm{mg} / \mathrm{dL}$ ), aspartate aminotransferase $176 \mathrm{U} / \mathrm{L}(13-30 \mathrm{U} / \mathrm{L})$, alanine aminotransferase 146U/L (10$42 \mathrm{U} / \mathrm{L})$, alkaline phosphatase $233 \mathrm{U} / \mathrm{L}$ $(38-113 \mathrm{U} / \mathrm{L})$, and gamma-glutamyl transpeptidase $695 \mathrm{U} / \mathrm{L}(9-32 \mathrm{U} / \mathrm{L})$; hemoglobin was within the normal limit. CT showed a diffuse high-density structure in the $\mathrm{CBD}$, with the bile duct mildly dilated ( $\triangleright$ Fig. $\mathbf{3 a}$ ). ERC revealed post-EST bleeding and a biliary clot in the CBD ( Fig.3b, > Fig.4a). The clot was removed using a grasping forceps and wire basket ( $>$ Fig. $\mathbf{3 c}$, $>$ Fig. $\mathbf{4 b}$ ), and an endoscopic biliary stent (EBS) was inserted into the CBD for biliary drainage. Clipping was applied to stop the bleeding ( $>$ Fig.3d, $>$ Fig. 4 c, d, $>$ Video 1). The patient progressed well after the procedures. The EBS was removed 8 days postoperatively and the patient was discharged 10 days postoperatively.

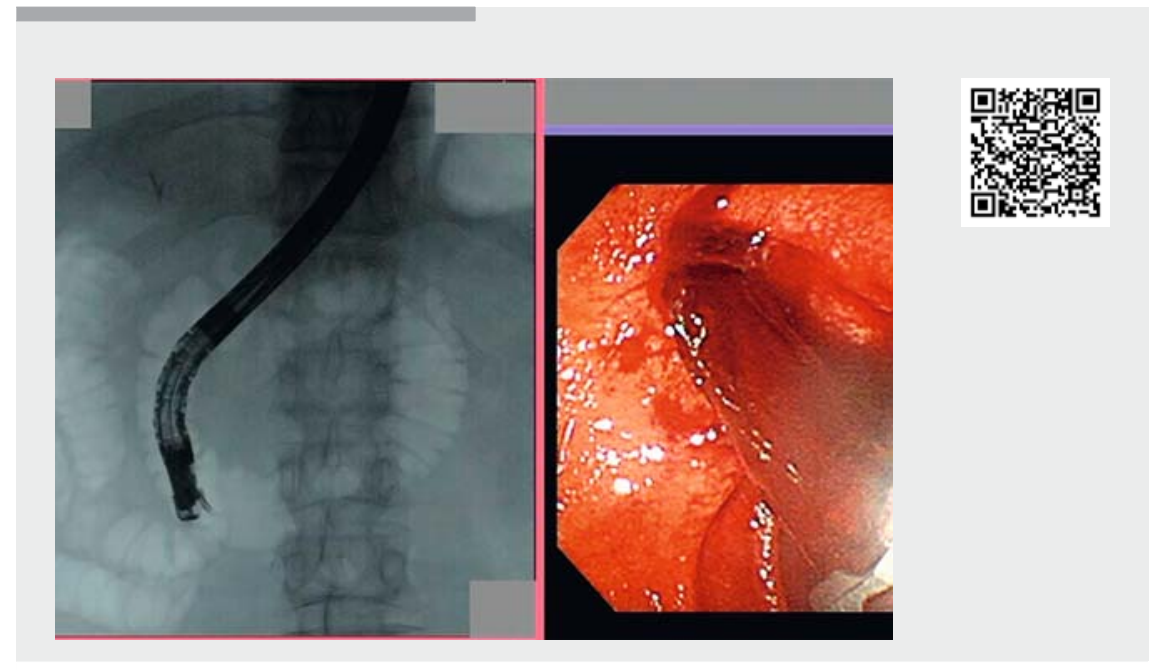

Video 1 The biliary clot, caused by delayed bleeding after endoscopic sphincterotomy, was removed using a grasping forceps and wire basket, and clips were applied to stop the bleeding.

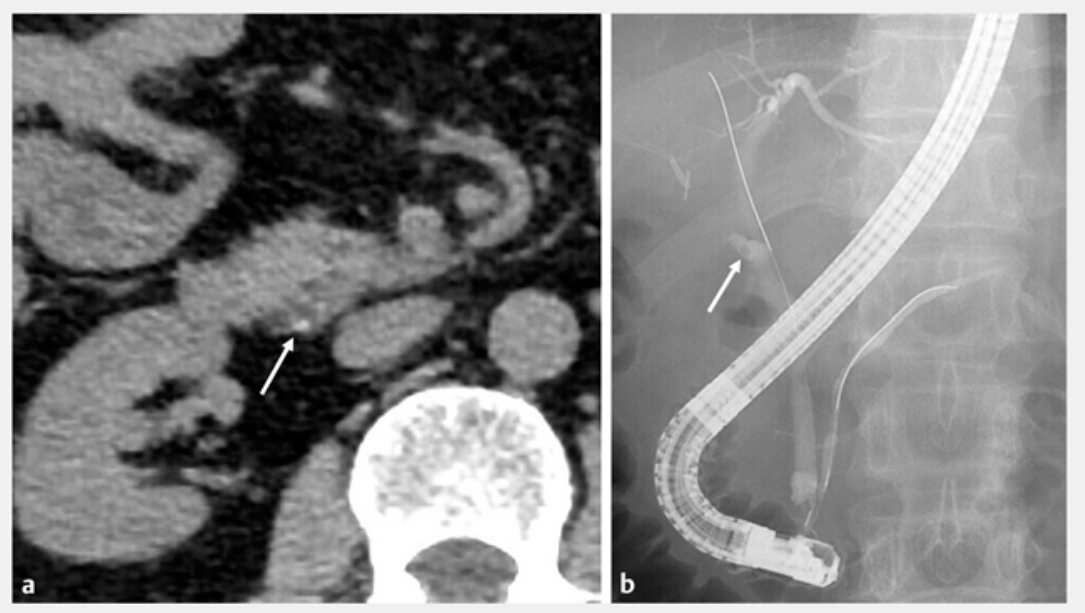

- Fig. 1 Common bile duct stone (arrow). a Abdominal computed tomography. b Endoscopic retrograde cholangiography. 

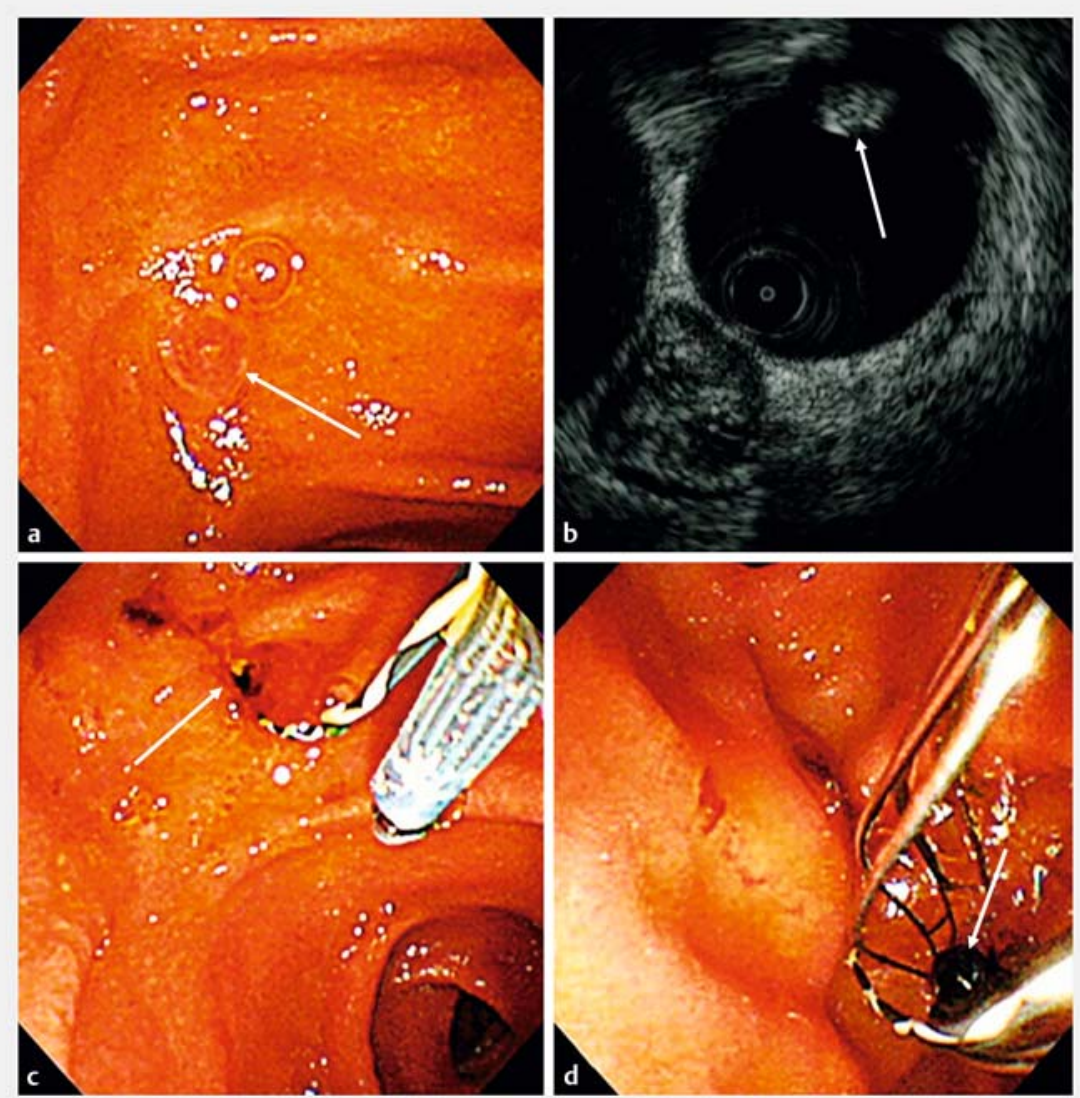

- Fig. 2 Removal of the common bile duct (CBD) stone. Endoscopic views (a, c, d) and intraductal ultrasonography (IDUS) view (b). a The ampulla of Vater was intact (arrow). b IDUS showed a CBD stone, approximately $2.8 \mathrm{~mm}$ in size (arrow). c Immediately after endoscopic sphincterotomy (arrow). d The CBD stone was removed using a wire basket (arrow).

The incidence of post-EST delayed hemorrhage is $1.62 \%$ [1], and biliary obstruction with a biliary clot caused by post-EST bleeding is extremely rare [2 5]. Endoscopic hemostasis is currently the first treatment choice for post-ERC bleeding, with balloon dilation and biliary stent placement used for treatment [2-5]. To the best of our knowledge, this is the first English case report of obstructive jaundice with a biliary clot caused by post-EST bleeding, treated with clipping and an EBS, which may be an effective endoscopic technique for treating such cases.

Endoscopy_UCTN_Code_CPL_1AK_2AC

\section{Competing interests}

The authors declare that they have no conflict of interest.

\section{The authors}

Takashi Abe', Takehiko Nariyasu' ${ }^{1}$, Takayuki Nagai ${ }^{1}$, Marina Hamamoto', Masato

Hanzawa', Yasuhisa Hiroshima ${ }^{1}$, Kazunari Murakami $^{2}$

1 Department of Gastroenterology, Oita Kouseiren Tsurumi Hospital, Beppu, Japan

2 Department of Gastroenterology, Faculty of Medicine, Oita University, Yufu, Japan

Corresponding author

\section{Takashi Abe, MD, PhD}

Department of Gastroenterology, Oita Kouseiren Tsurumi Hospital, Tsurumi 4333, Beppu City, Oita 874-8585, Japan Fax: +81-977-237884

takashi0315@oita-u.ac.jp 

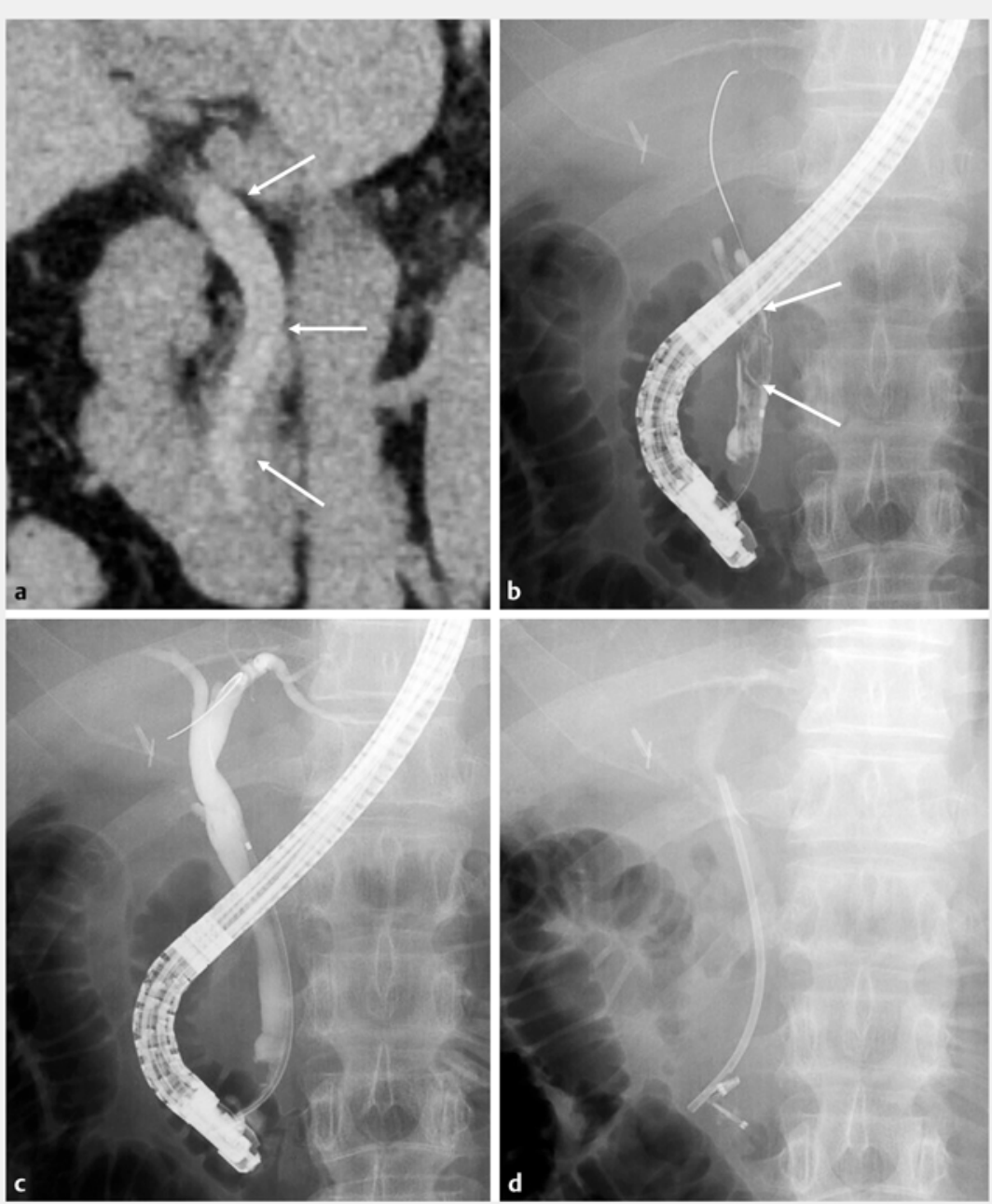

- Fig. 3 Imaging after endoscopic sphincterotomy (EST) and common bile duct (CBD) stone removal. a Reconstructed coronal image of abdominal computed tomography on day 4 after EST showed a diffuse high-density structure in the CBD with the bile duct being mildly dilated (arrows). b Endoscopic retrograde cholangiography revealed a diffuse filling defect in the CBD with the bile duct mildly dilated (arrows). c The CBD was cleaned up by removing the biliary clot using a grasping forceps and wire basket. $\mathbf{d}$ An endoscopic biliary stent was inserted into the CBD and clipping was applied for endoscopic hemostasis.

\section{References}

[1] Yan J, Zhou CX, Wang C et al. Risk factors for delayed hemorrhage after endoscopic sphincterotomy. Hepatobiliary Pancreat Dis Int 2020. doi:10.1016/j.hbpd.2019.12.010

[2] Mosenkis BN, Brandt LJ. Bleeding causing biliary obstruction after endoscopic sphincterotomy. Am J Gastroenterol 1997; 92 : 708-709

[3] Ala A, Khin CC, van Someren N. Common bile duct thrombus: a cause of persisting obstructive jaundice after endoscopic sphincterotomy. Gastrointest Endosc 1999; 50: 285-286

[4] Ergül B, Koçak E, Köklü S. An unusual complication of ERCP: obstructive jaundice due to a blood clot. Clin Res Hepatol Gastroenterol 2012; 36: e40-e41

[5] Zhu Y, Wang S, Zhao $S$ et al. Obstructive jaundice due to a blood clot after ERCP: a case report and review of the literature. BMC Gastroenterol 2018; 18: 163

\section{Bibliography}

Endoscopy 2021; 53: E297-E300

DOI 10.1055/a-1260-2903

ISSN 0013-726X

published online 8.10 .2020

(C) 2020. Thieme. All rights reserved.

Georg Thieme Verlag KG, Rüdigerstraße 14 , 70469 Stuttgart, Germany 

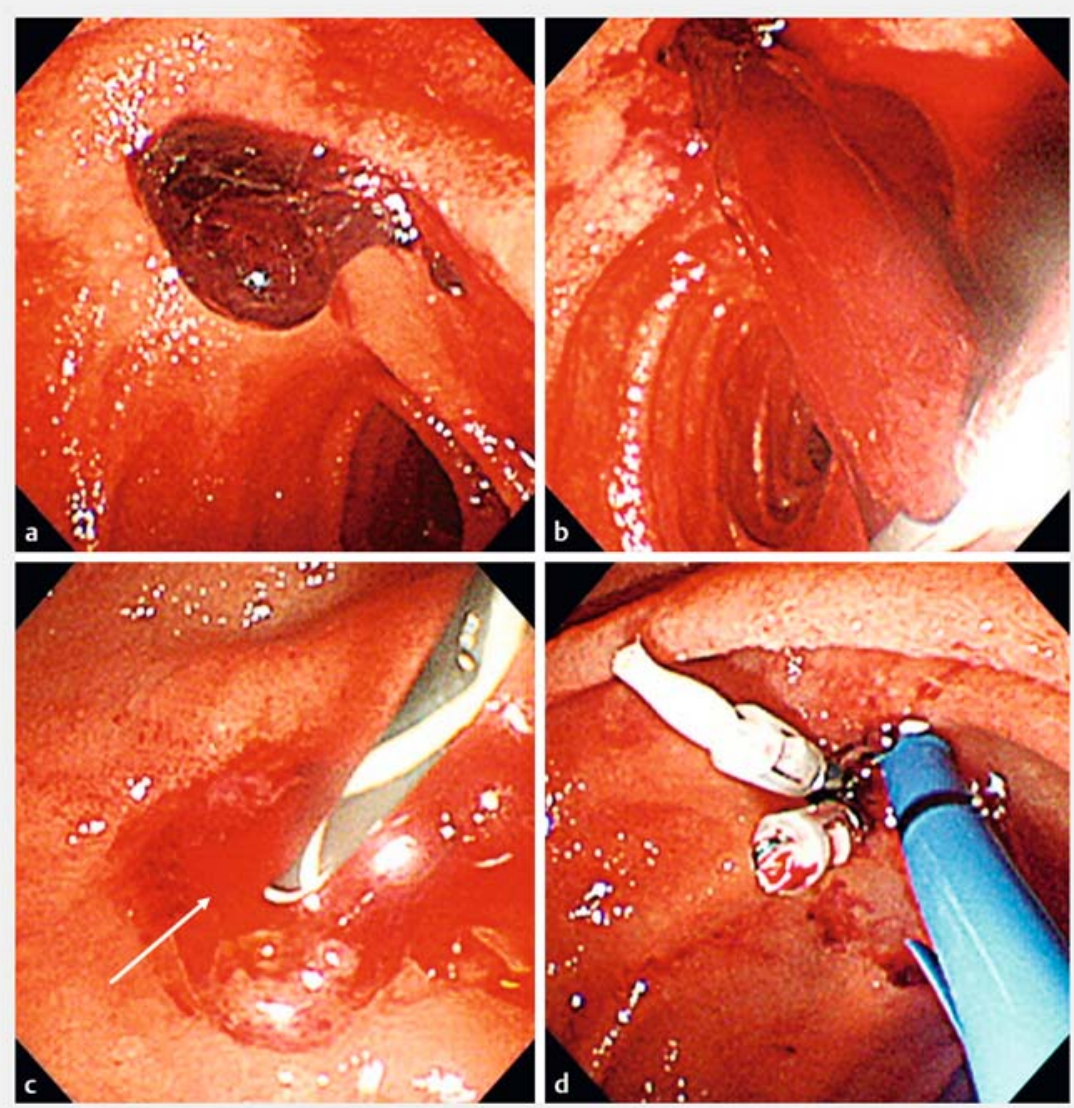

Fig. 4 Treatment of the biliary clot and delayed bleeding after endoscopic sphincterotomy (EST). Endoscopic views. a Post-EST delayed bleeding and the clot at the orifice of the common bile duct (CBD). b The biliary clot was removed using a grasping forceps. $\mathbf{c}$ The bleeding point was revealed (arrow). $\mathbf{d}$ An endoscopic biliary stent was inserted into the CBD and clipping was applied to stop the bleeding.

\section{ENDOSCOPY E-VIDEOS}

https://eref.thieme.de/e-videos

回直 Endoscopy E-Videos is a free access online section, reporting 回社: on interesting cases and new techniques in gastroenterological endoscopy. All papers include a high quality video and all contributions are freely accessible online.

This section has its own submission website at

https://mc.manuscriptcentral.com/e-videos 